\title{
A efetividade do jogo didático como facilitador no processo ensino-aprendizagem
}

\author{
The effectiveness of the didactic game as a facilitator in the teaching-learning process \\ La efectividad del juego didáctico como facilitador en el proceso de enseñanza-aprendizaje
}

\section{Resumo}

Tivemos como objetivo desta pesquisa avaliar a efetividade do jogo didático como facilitador no processo ensinoaprendizagem. Para tal utilizou-se uma estratégia qualitativa de pesquisa, de caráter exploratório, por meio de uma pesquisa de campo realizada com 9 alunos, estagiários do curso Técnico de Enfermagem numa instituição pública, a coleta de dados se deu através da aplicação de um jogo didático, após o jogo os alunos responderam a um questionário com perguntas que caracterizavam os participantes e avaliavam a efetividade do jogo. A análise dos instrumentos revelou que o jogo foi bem aceito, sendo ferramenta importante para o desenvolvimento da atividade $\mathrm{e}$ consequentemente na construção do conhecimento. Concluiu-se que a conscientização de professores sobre a importância de jogos didáticos é possível ao estimular a prática dessa metodologia como um viés facilitador de ensino aprendizado.

Palavras-chave: Avaliação educacional; Educação em enfermagem; Aprendizagem.

\begin{abstract}
The objective of this research was to evaluate the effectiveness of the didactic game as a facilitator in the teachinglearning process. For this purpose, a qualitative research strategy of exploratory nature was used, through a field research carried out with 9 students, trainees of the Nursing Technician course in a public institution, data collection was carried out through the application of a didactic game, after the game, students answered a questionnaire with questions that characterized the participants and evaluated the effectiveness of the game. The analysis of the instruments revealed that the game was well accepted, being an important tool for the development of the activity and, consequently, for the construction of knowledge. It is concluded that the awareness of teachers about the importance of educational games is possible by encouraging the practice of this methodology as a facilitator of teaching and learning.
\end{abstract}

Keywords: Educational assessment; Nursing education; Learning.

\section{Resumen}

El objetivo de esta investigación fue evaluar la efectividad del juego didáctico como facilitador en el proceso de enseñanza-aprendizaje. Para ello, se utilizó una estrategia de investigación cualitativa de carácter exploratorio, a través de una investigación de campo realizada con 9 estudiantes, becarios del curso de Técnico en Enfermería en una institución pública, la recolección de datos se llevó a cabo mediante la aplicación de un juego didáctico, luego de la juego, los estudiantes respondieron un cuestionario con preguntas que caracterizaron a los participantes y evaluaron la efectividad del juego. El análisis de los instrumentos reveló que el juego fue bien acogido, siendo una herramienta importante para el desarrollo de la actividad y, en consecuencia, para la construcción del conocimiento. Se concluye que la conciencia de los docentes sobre la importancia de los juegos educativos es posible fomentando la práctica de esta metodología como facilitadora de la enseñanza y el aprendizaje.

Palabras clave: Evaluación educativa; Educación en enfermería; Aprendizaje. 


\section{Introdução}

Para Fortuna (2016), a educação tem caráter permanente. Não há seres educados e não educados, estamos todos nos educando. Existem graus de educação, mas estes não são absolutos. Conforme Almeida e Silva (2019) a educação deve acontecer na forma de construção, ou seja, os alunos devem ser os agentes de seu próprio aprendizado, mas para a ocorrência desse aprendizado eles necessitam ser instrumentalizados.

$\mathrm{O}$ ato de ensinar é antigo. Arte e ensino têm caminhado juntos durante gerações e é possível perceber este entrosamento em materiais de didático gerados a partir de gravuras, sons, vídeos e expressões corporais diversas (Lima \& Lima, 2019).

O ensino tradicional é centrado na figura do docente, ele é o possuidor do conhecimento, não desenvolvendo práticas de ensino, levando o aluno a assimilar o que lhe é imposto sem realizar muitos questionamentos, dificultando assim o desenvolvimento do pensamento crítico (Mello, 2015).

Nos últimos tempos, com a grande mudança de valores, não é possível ensinar no modelo tradicional, pois estes deixam de corresponder às necessidades atuais do aluno. Com a globalização, é preciso prepará-lo para o mundo desenvolvendo a capacidade de análise crítica. Portanto torna-se necessário se preocupar no "como" ensinar e não somente "o que ensinar", sem esquecer os objetivos educacionais, ou seja, “porque” ensinar (Oliveira, 2018).

A concepção de educação varia com o perfil social dos indivíduos e suas necessidades, cabendo a adaptação e busca de soluções e tecnologias inovadoras para melhoria do ambiente comunitário através da implementação de práticas pedagógicas eficazes (Camillo \& Medeiros, 2018). Inovar é explorar novas ideias por intermédio de conexões, interações e influências com vistas a solucionar demandas inerentes às pessoas e locais para o qual a inovação será destinada (Balbino et al., 2020).

Novas estratégias de ensino permitem que o aluno desenvolva o interesse pelo assunto a ser discutido. O docente ao desenvolver novas propostas didáticas pedagógicas pode englobar diversos temas pertinentes ao grupo proposto. As estratégias de ensino tornam-se necessárias devido à mudança no âmbito escolar e a sociedade que evolui a cada dia (Moràn, 2015). A tecnologia está inserida no cotidiano do aluno e docente. Portanto, tornou-se necessário que o docente acompanhe a evolução tecnológica para uma melhor interação e desenvolvimento do conteúdo proposto.

Tecnologias podem proporcionar maior acesso e mais informações tanto para os profissionais como para a população em geral, dependendo da linguagem empregada, melhorando também a interação entre equipe e usuários (Prevedello et al., 2020).

$\mathrm{Na}$ enfermagem, os docentes vêm demostrando preocupações de como ensinar (Gonçalves \& Sanchez, 2016), porém normalmente são tentativas isoladas causando pouco impacto, não ocorrendo grandes transformações na educação

Não é possível realizar o exercício da enfermagem sem saber os fundamentos científicos e específicos que norteiam a prática do cuidado, sendo exercidos sem saber o porquê de sua utilização. A estimulação ao aluno pode ser realizada através do jogo, como recurso didático, por ser dinâmico e agradável (Costa et al., 2018). O jogo didático é uma ferramenta de ensino interessante e pode ser utilizado como recurso didático, oferecendo oportunidade a todos que estão naquele contexto educacional de construir conhecimento de uma forma mais dinâmica e lúdica, diferente do modelo tradicional de ensino.

Os jogos utilizam regras e têm por objetivo mostrar aos alunos um problema a ser resolvido e, assim, promover uma alternativa inovadora que possa atuar como elemento facilitador no processo de ensino-aprendizagem.

Para nortear a pesquisa utilizamos a seguinte questão: O jogo didático é um efetivo facilitador no processo ensinoaprendizagem? 
O objetivo desta pesquisa foi avaliar a efetividade do jogo didático como facilitador no processo ensinoaprendizagem.

O estudo justificou-se pela dificuldade dos alunos em campo de estágio e até mesmo no espaço de aprendizagem em compreender os objetivos da verificação dos sinais vitais e assim interpretá-los juntamente com a clínica dos clientes/pacientes obtendo uma melhor visualização de seu papel na equipe de enfermagem.

Tornou-se importante, devido à implementação de uma estratégia de ensino tendo como objetivo principal demonstrar a importância da verificação dos sinais vitais associando com a clínica dos clientes/pacientes, de forma lúdica. O intuito foi oferecer aos alunos oportunidade de aprendizagem diferenciada do modelo tradicional de ensino e estimular a curiosidade, o trabalho em equipe, a solução de problemas.

\section{Metodologia}

Este estudo baseou-se em uma estratégia qualitativa de pesquisa, de caráter exploratório, por meio de uma pesquisa de campo (Pereira et al., 2018).

A atividade proposta nesse estudo, foi a aplicação de um jogo didático com alunos em uma instituição educacional pública, no curso Técnico de Enfermagem, localizado na cidade de Volta Redonda/RJ.

O jogo apresentou como foco principal o tema Sinais Vitais e suas alterações relacionadas com o caso clínico do paciente/cliente, podendo o jogo educacional ser utilizado por outros seguimentos profissionais com outros conteúdos a serem abordados.

A coleta de dados ocorreu em salas de aulas com os alunos do curso Técnico de Enfermagem que realizam atividades no campo de estágio supervisionado, pois os mesmos já cursaram as todas as disciplinas teóricas do curso, não havendo comprometimento em relação ao conteúdo do jogo.

O jogo didático tem caráter cooperativo. Todas as perguntas contidas no jogo foram elaboradas pela autora do trabalho a partir da experiência profissional. Todas as respostas foram fundamentas bibliograficamente. A escolha do conteúdo das perguntas baseou-se: na identificação de temas complexos e relevantes para a enfermagem; de temas rotineiros para a equipe de enfermagem; de temas que os alunos em seu cotidiano apresentam dificuldades de assimilação.

O desenvolvimento do jogo ocorreu a partir de várias hipóteses, sendo definida a escolha de um jogo didático de lona, que foi fixado na lousa para se jogar. Não foi estipulado o número de participantes no jogo e conforme o número de participantes, a turma será dividida em grupos. Cada grupo pôde conter no máximo 05 alunos. Foram divididos os alunos em grupos para que todos tivessem oportunidade de responder mais de uma pergunta. A lona possuía desenhos retangulares com contornos arredondados (no qual a autora chamou de casa), numerados e escritos dentro delas às instruções diferenciadas para se jogar. O desenho teve 12 casas numeradas de 01 a 12. O início do jogo ocorreu através do grupo que retirou o maior número no dado.

Cada casa desenhada e numerada constava das seguintes frases: 1-Tem direito à ajuda de um amigo de outro grupo a sua escolha; 2-Boa sorte. A professora indica 03 orientações; 3-Responda à pergunta da casa 07; 4-Responda à pergunta de $n^{\circ}$ 4 e logo após jogue outra vez; 5-Responda à pergunta de $n^{\circ} 05$. Você caiu na caixa preta; 6-Responda à pergunta; 7-Responda à pergunta da casa $03 ; 8$-Responda a pergunta da casa 10; 9-Escolha outro grupo para responder a pergunta; 10-Responda a pergunta da casa 08; 11-Responda a pergunta; 12-Responda a pergunta de $\mathrm{n}^{\circ} 12$. Você caiu na caixa preta.

O jogo constou de: 01 lona desenhada com 12 casas contendo informações para o processo do jogo, 12 lacunas à direita a ser colocado as tarjetas contendo as perguntas e 12 lacunas à esquerda a ser colocado as tarjetas de respostas, 01 dado simples, numerado de 01 á 06, com o objetivo de retirar a ordem de início dos jogadores. Possuía 12 peças numeradas dentro 
de um saco de pano, com a finalidade de realizar o sorteio das peças numeradas que indicavam qual casa o jogador realizará a leitura e consequentemente a pergunta que foi discutida pelo grupo. Teve 12 tarjetas com respostas sobre a mesa e 01 caixa preta contendo 08 perguntas.

Ao retirar-se uma peça numerada no saco de pano um participante do grupo leu a instrução da casa correspondente desenhada na lona. O professor realizou a pergunta do número correspondente para o grupo e logo em seguida colocou a tarjeta da pergunta na lacuna à direita correspondente a sua numeração. Os participantes do grupo escolheram apenas uma tarjeta de resposta sobre a mesa e colocou ao lado da pergunta no jogo (lacuna à esquerda) realizando a leitura da resposta escolhida. Caso o grupo não acertasse a resposta, o professor repetiria novamente a pergunta para que todos os participantes do jogo tenham a oportunidade de respondê-las. O grupo que soube a resposta correta e levantou a mão em primeiro lugar teve o direito de ir à mesa e pegar a tarjeta correspondente. Se o grupo errasse a resposta, a professora diria 03 orientações contendo 03 opções de respostas a todos os participantes. As 03 opções constariam de 01 resposta correta e 02 respostas incorretas. As opções de respostas tinham por objetivo a construção do saber, fazendo com que todos refletissem e conseguissem alcançar a resposta correta. O grupo que soubesse a resposta correta e levantar a mão em primeiro lugar teve o direito de apenas um participante ir até a mesa, pegar a tarjeta correspondente. Se o grupo errasse a resposta correspondente à pergunta, o professor pegaria a tarjeta correta, colocaria ao lado da pergunta e realizaria a discussão. O jogo continuou com o grupo estabelecido pela ordem de ser jogar.

Todas perguntas e respostas tinham 03 opções de respostas. As opções eram utilizadas somente quando os participantes não sabiam a resposta correta, ou algum dos participantes estivesse na casa Boa Sorte.

O jogo possuía uma caixa preta a parte, contendo em seu interior 08 perguntas. O grupo que fosse responder as perguntas das casas de $\mathrm{n}^{\circ} 5$ e 12 teria que responder as perguntas respectivas aos números, e também a que constava dentro da caixa preta. As perguntas da caixa preta, não possuíam tarjetas de resposta, o próprio grupo teria que formular a resposta, portanto não possuiria tarjeta a ser colocada ao lado da pergunta. Se o grupo não soubesse formular a resposta, a pergunta era realizada a todos os participantes, caso nenhum participante soubesse a resposta, o professor iria dizer as 03 opções da carta, se mesmo assim os participantes não soubessem responder a professora formularia a resposta e discutiria com o grupo.

Após cada resposta correta o professor discutiu com os participantes as respostas baseadas na bibliografia.

Os dados coletados foram categorizados de acordo com a proposta por Minayo Deslandes, e Gomes (2012), que parte das seguintes fases: leitura exaustiva do material e pré-análise do mesmo; extração das palavras chaves e unidades temáticas; construção dos eixos temáticos e categorização para análise e interpretação dos mesmos. Segundo Minayo Deslandes, e Gomes (2012) a técnica de categorização é aquela que se têm dados construtivos, estruturando-se a partir de lógicas de acordo com o seu objetivo e são constituídas por estudos básicos que ajudam a desenvolver projetos.

Esta pesquisa foi aprovada pelo Comitê de Ética em Pesquisa do Fundação Oswaldo Aranha sob o número CAAE 04665012.6 .0000 .5237 .

Para preservar o anonimato dos participantes, na apresentação dos resultados, os profissionais envolvidos na pesquisa foram nomeados com a letra "A" e o número sequencial.

\section{Resultados e Discussão}

Foi aplicado o jogo didático a uma turma de uma instituição privada, onde 09 alunos participaram. Todos os participantes são do sexo feminino e a média de idade dos participantes é de 28,22 anos. Todos possuiam segundo grau completo visto que o curso tinha seu funcionamento com o oferecimento na modalidade de Pós Médio. De todos os participantes 4 delas já possuíam o Curso de Auxiliar de enfermagem 


\section{A efetividade do jogo didático como facilitador no processo ensino-aprendizagem}

Os resultados revelaram que a atividade chamou a atenção para a situação do cliente/paciente. A importância dessa experiência foi estimular o aluno e fazer com que ele visualize o seu papel na equipe de enfermagem, e como a sua assistência é indispensável na realização do cuidado ao cliente/paciente. Todos concordaram que os "Sinais Vitais" não são apenas números, mas sim, dados essenciais para a enfermagem na prestação do cuidado, conforme fala do aluno participante:

"As perguntas fazem parte do dia a dia do técnico de enfermagem." A9

Na concepção de (Lima et al., 2021) os jogos didáticos vão além do entretenimento, eles têm por objetivo ensinar e educar e se constituem em ferramentas eficientes de ensino e aprendizagem. Porém o docente deve planejar, organizar e controlar as atividades de ensino utilizando recursos tecnológicos apropriados a fim de criar as condições ideais para que os alunos dominem e compreendem os conteúdos, desenvolvam a iniciativa, a curiosidade, a disciplina, o interesse, a independência, a criatividade e a visão crítica.

"Foi bem elaborado. Respostas precisas e diretas." $A_{7}$

Conforme registros da autora no decorrer da aplicação do jogo, as falas dos alunos foram interessantes e relevantes para análise desse estudo. A primeira fala dos alunos é em relação ao médico.

"Apenas o médico pode estabelecer planos de cuidados a partir das situações que o paciente se encontra, juntamente com os dados obtidos através da verificação dos Sinais Vitais" $A_{3}$

Este dado revelou que o técnico de enfermagem ainda não percebeu a importância do seu papel na equipe multiprofissional. Quando ocorrem alterações nos Sinais Vitais, deve-se comunicar imediatamente ao médico, porém há situações que a enfermagem pode agir, visando à qualidade de sua assistência e consequentemente a melhora do paciente/cliente. O técnico de enfermagem ao assimilar a teoria estudada e aplicada na prática desenvolve uma assistência mais segura, pois está um passo a frente do que pode vir acontecer com o paciente/cliente.

Os jogos apresentam de forma atraente os problemas, estimulando a curiosidade e o interesse dos participantes e sua criatividade para elaborar estratégias de resolução (Santos \& Oliveira, 2018). A utilização de jogos didáticos como alternativas inovadoras para apresentar os conteúdos possibilita aumentar a disseminação nos campos do conhecimento que tocam a vida cotidiana dos estudantes.

Foi possível observar muita insegurança dos alunos em relação às suas falas e atitudes. Das questões aplicadas, 04 alunos acertaram as questões diretamente, os demais revelaram dificuldades de desenvolvimento. Quando o professor realizou a discussão das questões amparadas na bibliografia, os alunos mostraram dificuldades, principalmente em associar as alterações dos Sinais Vitais com o que o paciente apresentava dificultando a relação do cuidado com os sinais vitais apresentados pelo paciente.

Quando solicitamos a opinião dos alunos em relação a atividade, algumas falas foram relatadas:

"Perguntas bem elaboradas, pois faz usar bem o raciocinio e pensamento rápido, se o objetivo do jogo era esse. A6 
Ao usar os jogos na escola, os docentes precisam ter a clareza do porquê de estarem utilizando-os. O jogo não pode ser visto só para preencher um tempo de aula quando o docente não tem mais atividades e conteúdo a serem desenvolvidos.

"Perguntas foram todas voltadas para o que estudamos, foi bom para testar nossos conhecimentos, já que foi de surpresa." $A_{5}$

Não é simplesmente dizer que usa o jogo, e oferecer qualquer jogo aos alunos sem nenhum objetivo. O que o docente necessita é saber o objetivo de se utilizar o jogo como ferramenta pedagógica, desenvolvendo uma proposta lúdico-educativa, gerando situações estimuladoras e eficazes para a aprendizagem, observados na fala do participante:

“Foi bom jogar, prende a atenção e aumenta a capacidade de percepção e avaliação.” $A_{2}$

O lúdico é um desafio tanto para os alunos como para os docentes, pois ambos precisam estar preparados para trabalharem de uma forma diferenciada daquela a que estavam acostumados, procurando aproveitar o máximo das contribuições que a proposta tem a oferecer para a construção do conhecimento do aluno, o lúdico e o raciocínio lógico devem estar presentes nesse processo de aprendizagem (Bandeira \& Souza, 2015). Em relação ao desenvolvimento de estruturação do jogo conseguiu-se extrair a seguinte fala:

“As regras estão muito boas não precisa ser mudada.” $A_{4}$

A simulação de diversas situações com conteúdo reais foi extremamente envolvente e importante para o aluno, tendo a oportunidade de experimentar o gosto pelo cuidar, de planejar, visualizar e compreender o cuidado de enfermagem, o jogo é uma atividade há tempos utilizada, historicamente o ser humano, tem como cultura a atividade lúdica, e por meio da ludicidade o indivíduo é socializado. Entre algumas atividades lúdicas, destacamos o jogo (Carvalho, 2016). O jogo serviu de elemento estimulante para estudos posteriores, observado na fala do participante:

Acho que será bom se nós tivermos acesso a essas perguntas e respostas para estudarmos mais. ” A8

O jogo nem sempre foi visto como didático, sendo relacionado ao prazer, a diversão. Atualmente são associados à educação, porém pouco utilizado devido ao desconhecimento dos docentes, através da conscientização de professores sobre a importância de jogos didáticos é possível estimular a prática dessa metodologia como um viés facilitador de ensino aprendizado (Almeida et al., 2021). É importante a utilização desses recursos didáticos que podem facilitar a consolidação do conhecimento dos alunos, além de permitir aos mesmos uma outra visão acerca do mundo a sua volta (Oliveira Júnior et al., 2020).

Os jogos didáticos desempenham um importante papel no processo educativo. É necessário no desenvolvimento intelectual do aluno em vários aspectos, tais como, no aspecto físico, emocional, raciocínio lógico e na formação de uma consciência crítica, social, criativa, entre outras (Xavier et al., 2021).

Os jogos didáticos possuem o objetivo de demostrar as diferentes formas do grupo se relacionar e posteriormente estimular a convivência e definir através das experiências proporcionadas pelo jogo a socialização e integração dos alunos (Nascimento et al., 2010). 
Um dos objetivos principais dos jogos didáticos é eliminar o individualismo, gerando a cooperação nas pessoas, respeitando os limites e convivendo com o potencial de cada um (Santos \& Oliveira, 2018), pode-se ajudar os estudantes a adquirir as capacidades necessárias para utilização tecnologias de informação, buscar, analisar e avaliar informações, solucionar problemas e tomar decisões (Rocha et al., 2019).

Assim, pode-se dizer que os jogos didáticos são importantes na escola para a educação integral dos alunos, desenvolvendo a autoestima, sentimento de aceitação e proporcionar oportunidades de confiarem em si mesmas, colaborando na formação dos pensamentos e da visão crítica não perdendo de vista a sua principal característica que consiste em eliminar qualquer forma de competição.

\section{Conclusão}

Após a execução da atividade, observou-se que a maioria dos alunos considerou a associação da técnica executada ao cuidado de enfermagem interessante. Portanto o resgate e a valorização dos sinais vitais foi um fator relevante para qualidade da assistência de enfermagem. Alguns alunos relataram o desconhecimento da importância sobre os sinais vitais.

Apresentar ao aluno a importância da interpretação das técnicas, não somente os sinais vitais como todas as outras é de grande valia. O jogo foi uma ferramenta importante para o desenvolvimento da atividade e consequentemente na construção do conhecimento.

As observações dos resultados desta pesquisa, juntamente com a experiência profissional do autor, nos motivam ainda mais no desenvolvimento e na elaboração de novas tecnologias de ensino, que buscam a cooperação, o incentivo na busca de resolução de problemas em salas de aula, da interação entre a técnica executada associada à finalidade de sua realização cientificamente, e não meramente a realização sem fundamentação, incentivando o aluno na construção do conhecimento. Isto favorece o fortalecimento da importância do papel do técnico de enfermagem, buscando cada vez mais a qualidade da assistência.

Limitações e dificuldades na realização do estudo existiram, algumas delas impossibilitaram o desenvolvimento da coleta de dados devido à resistência de algumas instituições em participar da pesquisa, limitando da entrada de pesquisadores, isto não diminuiu a magnitude e a importância deste estudo. Sugere-se o desenvolvimento de novos estudos e pesquisas com o desenvolvimento de novas tecnologias permitindo assim a melhora da qualidade do aprendizado, visto que se demonstrou um estudo fértil para a área de ciências do cuidado em saúde e educação.

A conscientização de professores sobre a importância de jogos didáticos foi possível ao estimular a prática dessa metodologia como um viés facilitador de ensino aprendizado

\section{Referências}

Almeida, F. S., Oliveira, P. B. de, \& Reis, D. A. dos. (2021). A importância dos jogos didáticos no processo de ensino aprendizagem: Revisão integrativa. Research, Society and Development, 10(4), e41210414309. https://doi.org/10.33448/rsd-v10i4.14309

Almeida, J. C. M., \& Silva, W. R. (2019) A construção do conhecimento através da relação professor/aluno. Revista Científica Multidisciplinar Núcleo do Conhecimento. 10(3),81-97.

Balbino, C. M., Silvino, Z. R., Joaquim, F. L., Souza, C. J. de, \& Santos, L. M. dos. (2020). Inovação tecnológica: perspectiva dialógica sob a ótica do Joseph Schumpeter. Research, Society and Development, 9(6), e198963593. https://doi.org/10.33448/rsd-v9i6.3593

Bandeira, P. O., \& Souza, P. K. T. D. (2015). O lúdico e suas contribuições na educação infantil. https://repositorio.ufpb.br/jspui/handle/123456789/2431

Camillo, C. M., \& Medeiros, L. M. (2018). Teorias da educação. https://repositorio.ufsm.br/bitstream/handle/1/18360/Curso_Lic-Ed-Camp_TeoriasEduc.pdf?sequence $=1 \&$ isAllowed $=\mathrm{y}$

Carvalho, M. D. C. D. (2016). A importância do brincar na construção de conhecimentos de crianças na pré-escola (Doctoral dissertation). http://hdl.handle.net/10284/6928 
Research, Society and Development, v. 10, n. 10, e305101018748, 2021

(CC BY 4.0) | ISSN 2525-3409 | DOI: http://dx.doi.org/10.33448/rsd-v10i10.18748

Costa, R. C., Miranda, J. C., \& Gonzaga, G. R. (2018). Avaliação e validação do jogo didático "Desafio Ciências-sistemas do corpo humano" como ferramenta para o Ensino de Ciências. Revista de Ensino de Ciências e Matemática, 9(5), 56-75.

Fortuna, V. (2016). A relação teoria e prática na educação em Freire. Revista Brasileira de Ensino Superior, 1(2), 64-72.

Gonçalves, M. E. D. S., \& Sánchez, D. S. (2016). Concepção do enfermeiro docente sobre meio ambiente e Educação Ambiental e sua interface com as práticas pedagógicas em educação ambiental. Rev. Educação Ambiental em ação.

Lima, I. M. A, Lima, X. M. A. Os paradigmas da educação nas civilizações antigas e a preparação dos pesquisadores da antiguidade. Revista Científica Multidisciplinar Núcleo do Conhecimento. Ano 04, 05, 100-109.

Mello, R. D. (2015). Dificuldades e possibilidades relatadas no estágio supervisionado em ciências. https://rd.uffs.edu.br/handle/prefix/2678

Minayo, M. C. S., Deslandes, S. F., \& Gomes, R. (2012). Pesquisa social: teoria, método e criatividade. Vozes.

Morán, J. (2015). Mudando a educação com metodologias ativas. Coleção mídias contemporâneas. Convergências midiáticas, educação e cidadania: aproximações jovens, 2(1), 15-33.

Oliveira Júnior, C. I. de, Cardoso, A. T., Rodrigues, R. P., Resende, R. X., Oliveira, G. F. de, \& Klein, K. V. (2020). Jogos e aprendizado: ensinando propriedades coligativas por meio de um jogo didático. Research, Society and Development, 9(4), e118942925. https://doi.org/10.33448/rsd-v9i4.2925

Oliveira, D.C. A Importância da Didática no Ensino Fundamental. Revista Científica Multidisciplinar Núcleo do Conhecimento. 06(04),140-157.

Pereira, A. S., Shitsuka, D. M., Parreira, F. J., \& Shitsuka, R. (2018). Metodologia da pesquisa científica. UFSM. https://repositorio. ufsm. br/bitstream/handle/1/15824/Lic_Computacao_Metodologia-Pesquisa-Cientifica. pdf

Prevedello, B. P., Dotto, P. P., \& Santos, B. Z. dos. (2020). Animação no formato de vídeo como tecnologia para a promoção do aleitamento. Research, Society and Development, 9(1), e199911864. https://doi.org/10.33448/rsd-v9i1.1864

Santos, G. S.; \& Oliveira, M. F. A. (2018). O jogo como recurso didático para o ensino de nutrição: na Trilha dos nutrientes. Ensino, Saúde e Ambiente, 11(3), $1-27$.

Rocha, P. C. S., Jucá, S. C. S., Silva, S. A. da, \& Monteiro, A. de O. (2019). Competências digitais na perspectiva da informação, conhecimento e aprendizagem. Research, Society and Development, 8(8), e42881241. https://doi.org/10.33448/rsd-v8i8.1241

Xavier, A. R., Barbosa, M. K. R., Muniz, K. R. de A., Andrade, F. A. de, Santana, J. R., Vasconcelos, J. G., Scipião, L. R. de N. P., Carvalho, E. de F. G. de, Ferreira, A. D., \& Santos, M. J. C. dos. (2021). Saberes populares, Etnomatemática e o uso de Jogos no ensino de Geometria. Research, Society and Development, 10(1), e50910111998. https://doi.org/10.33448/rsd-v10i1.11998 